\title{
The Effect of Digital Technology in Promoting Democracy: A Case Study of Hong Kong Alliance
}

\author{
Shi Zhang
}

The University of Melbourne, Australia

\begin{abstract}
Since June fourth, 2019, the $30^{\text {th }}$ anniversary of the June Fourth massacre, mass protests have erupted across Hong Kong and continued today. The protest has evolved from Anti-Extradition Law Amendment Bill Movement to calling on the radical democratic reform. A typical characteristic of this protest is that digital technologies play a significant role in the whole process. Thus, this paper chooses a representative activism organization, namely Hong Kong Alliance (Hong Kong Alliance in Support of Patriotic Democratic Movements of China), to analyze and evaluate the role and effect of digital technologies in influencing the political campaign in the digital age. Specifically, this paper employs the connective and collective action theory to analyze the organizational structure and the operation mode of Hong Kong Alliance, and focus on the digital storytelling strategy that Hong Kong Alliance employed. With the criteria for assessing digital movement purposed by Yana Breindl (2013), the researcher in Oxford internet institute, the University of Oxford, this research finds that Hong Kong Alliance has generated significant awareness among the public, and perceived the actual legitimate interlocutors and triggered certain political and legal changes, although there are still some controversial issues. Furthermore, it is also found that the gap between the existing evaluation framework and the real situation of digital movement is notable. In other words, the static evaluation criterion maybe not appropriate in the current digital space, while a dynamic appraisal method which does not only assess the result but also consider the value of the process is in need in the future study.
\end{abstract}

Keywords: Digital technology, Democracy, Digital activism, Collective action, Digital storytelling, June Fourth Incidence

\section{Introduction}

On May sixteenth, 2019, Kay Ivey, Governor of Alabama, signed the abortion bill into law, which sparked a strong outcry in the digital space. For instance, Rihanna posted the photos of all senators who voted in favor. Jameela Jamil, a British TV presenter and actress, shared her own story of having an abortion when she was young. Moreover, with the help of Hashtag \#YouKnowMe, people around the world have participated in the discussion (Chambers, 2019). It could be seen that digital space had become a significant place for people to give out their voice when a social or political issue happened in today's world. Digital technology is fundamentally changing the way of political participation, and it is generally believed that the role of digital technologies in promoting social and political movement is effective (Ruth, 2018, Shirky, 2011, Kaun, 2017).

However, people may ignore an important precondition that the access to digital space and the free flow of information in the digital space are guaranteed by democracy, which might exaggerate or disturb the evaluation of the real effect of digital technologies (Kirsty, 2012). On June fourth, 2019, China's government blocked all the overseas Weibo accounts to silence the 30th anniversary of June fourth Massacre, also known as the Tian'anmen Massacre, where thousands of students and protestors were killed (Moritsugu, 2019). Chinese government's behavior exactly reflects the "instrumental approach" of digital technology described by Clay Shirky. The "instrumental approach" highlights the tool attribute of digital technologies, indicating that authority could use it to throttle democracy and freedom (Shirky, 2011, p.4). However, does this mean the internet-based form of democracy is impossible? Alternatively, even say that digital technology enhances despotism. 
This paper places this question in the intersection of globalization, digitization, and the non-democratic world and chooses HK Alliance (Hong Kong Alliance in Support of Patriotic Democratic Movements of China) as the study case to analyze how they use digital space to promote democracy. Specifically, this paper will firstly introduce the historical context of the HK Alliance and its political appeals. Then this paper will employ collective action theory (Bennett \& Segerberg, 2012) to analyze its organizational structure and operation mode, and employ a digital storytelling perspective to analyze its specific actions. In the end, this paper will evaluate the actions of HK Alliance and theoretically discuss the existing evaluation criterion of organizations aiming at promoting democracy in the digital age.

\section{The historic context}

HK Alliance is the abbreviation of Hong Kong Alliance in Support of Patriotic Democratic Movements of China, which was established in 1989 pro-democracy movement. It has five operational goals, including releasing the dissidents, rehabilitating the 1989 pro-democracy movement, demanding accountability of the June fourth massacre, ending one-party dictatorship, building a democratic China (Hong Kong Alliance, 2015.). It could be seen that HK Alliance's political appeals are based on the 89' democracy movement and point to the fundamental democratic reform in China. For a better understanding of HK Alliance, it is necessary to approach the 89' democracy movement, also known as the June Fourth Incident, which was regarded as a watershed in the process of democratization in China (Li, Mark, Li, \& Hoopla, 2011)

After the reform and opening-up, China experienced rapid economic development in the 1980s, which caused a series of social changes. As a result, the awareness of democracy and freedom rapidly grew and spread. People, particularly for students and political elites, began to concern the future of China. Yaobang $\mathrm{Hu}$, the then chairman of the Chinese Communist Party, actively supported the democracy reform, which dramatically strengthened the innovationist (Calhoun, 1989). However, the fast development of the economy also shocked the economic structure and caused a series of problems. For example, the market economy under the management of the single-party system led to severe inflation, corruption, and employment problem for students, which drew the foreshadowing of the protest (Brook, 1998, p. 216). The discontent emotion broke out in April 1989 when Yaobang Hu passed away. People from different parts of China gathered in Tian'anmen square to mourn for him, which evolved into protest after several student leaders made speeches in the crowd(Lim, 2014, p. 34-35). On May twentieth, the Chinese government motivated over 300,000 troops to suppress the protest, which caused mass bloodshed (Thomas, 2006). On the next day, the armed suppression sparked the largest protest ever happened in Hong Kong. Over 1 million Hong Kong citizens marched on the street to support the protest in Beijing. During the march, "Hong Kong Alliance in Support of Patriotic Democratic Movements of China" was proclaimed (Hong Kong Alliance, 2015).

Before the digital age, the activity of HK Alliance was strictly restricted, and the Chinese government could effectively block the information about the June fourth Incident by expelling foreign journalists and controlling coverage of the events in the domestic press (Miles, 1997, p. 28). However, the rise of digital technology brought new opportunities. For HK Alliance, their focus has shifted to the digital space. They did not only set up a website but also employed diversified digital methods to pursue their political appeals. For example, they established a digital museum to collect and preserve evidentiary material about the June fourth Incidence. Also, they organized various online activities in diversified digital forms to attract different targeted groups. On the contrary, the rise of digital space is a severe challenge for the Chinese government. The ubiquitous digital networks have built an "environment" where the government has lost the absolute control of information (Shirky, 2011 p. 32-33). Although the Chinese government has blocked almost all the international digital platforms such as youtube, twitter, and flicker (Branigan, 2009), more and more Chinese people gradually get to know what happened on Tian'anmen square thirty years ago, and in this process, HK Alliance plays a significant role. 
Shi Zhang / The Effect of Digital Technology in Promoting...

\section{Literature review and theory underpinning}

Jürgen Habermas considered the public sphere as the foundation of modern democracy. According to Habermas (1999, p. 36), the public sphere has three features, including the disregard of status, which requires the "sphere" disregard the status of participants; The domain of common concern, which emphasizes that what to discuss in the public sphere should also be decided by the public rather than authority; The inclusivity, which highlights the openness of the public sphere. His theoretical framework provides a superstructure for other studies to explain the relationship between digital technology and democracy. Longe, Danquah, and Ebem (2012, p.46) found that people can anonymize not only their names but also almost anything that could expose their status in real life. However, the openness of the digital space and the fluidity and negotiability of digital information are controversial. Nakamura (2008) argues that the internet is not equally accessible for everyone in the world because of the regional differences in global internet development. Yu, L. et al. (2018, p. 370-373) argue that people do not equally participate in the internet even in the same society because of individual differences, for instance, age. However, Grubenmann, Rimscha and Siegert (2017) thought that people in the digital age are much better informed than before. They admitted the existence of border and resistance factors in the digital information flow, whereas they highlighted that users today have more possibilities to publish, get informed or communicate, and to reach a bigger audience.

Similarly, the disagreement emerges when the study specifically focuses on the relationship between digital technology and authority. When discussing the effect of digital technologies in influencing democracy, the view of the "instrument approach" argues that digital technologies could damage democracy and help the government suppress the public through surveillance and censorship (Shirky, 2011 p. 30-31). However, an opposing view believes that what digital space has established for the government is not a "tool" but an "environment" where the authority has lost the absolute control of information (Shirky, 2011 p. 32-33). On the one hand, people record and report events with their phones, camera, and other mobile devices, which radically breaks the information monopoly of authority. On the other hand, the shared awareness is wide accepted by the public in this digital environment, which creates what the media theorist Briggs called "the conservative dilemma," or called "the dictator's dilemma." (Briggs \& Burke, 2009). Ethan Zuckerman, the researcher of Harvard's Berkman Center, described this phenomenon as "the cute cat theory." He argued that shutting down a multipurpose digital platform could provoke a more massive public outcry than shutting down an obscure one (Zuckerman, 2008).

The opposite views make it significantly valuable to conduct the practical investigation of a specific case on the actual effect of digital technology in influencing the democratization process. Although many pieces of research have studied varied aspects of digital movements like Metoo (Hansson et al., 2019), Blacklivesmatters (Haffner, 2019), and the Indignados (Bennett \& Segerberg, 2012), they generally lack a systematized structure to study "what it is," "How it works," and "How to evaluate it." Therefore, this study tries to map a comprehensive picture of HK Alliance, and unfold its role and effect in the digital space. Furthermore, in terms of the contrary, entangled, and the interactional relationship between the Chinese government and the Hong Kong Special Administrative Region, the study on HK Alliance, one of the leading organizations in the ongoing protest, has more practical and historical significance.

\section{Research method}

This paper conducts a case study on HK Alliance by employing collective and connected action theory, digital storytelling framework, and the assessing criterion purposed by Yana Breindl (2013) to comprehensively analyze the organization structure, the means of promotion, and the actual effect of HK Alliance. 
The data was collected from the published statement and report of HK Alliance, the online activities and videos from varied digital platforms, media coverage, and the relevant government documents. Specifically, to analyze the organization structure, this research collected the income and spending data of HK Alliance from its financial report between 1989 and 2018, and referenced the crowdfunding statement published in 2019. Besides, a songwriting workshop launched by HK Alliance on Facebook in May 2018 is also taken as an example to study the nature of its operational mode.

To analyze the use of digital storytelling, this research compares two stylized videos published by HK Alliance on Youtube. The first video is the narration of a mother called Xianling Zhang, published in 2010. The second video is the story of Xiaoxin Tang, published in 2018. The evaluation of HK Alliance is grounded on the framework proposed by Yana Breindl. Nine media coverage from seven news agency is selected for analyzing, including one from BBC, two from HongKong Free Press, one from New York Times, two from Aljazeera, one from the Voice of America, one from CNN Asia, and one from Telegraph UK.

\section{Collective action and HK Alliance}

According to Bennett and Segerberg (2012), there are two organizational modes of digital action, including collective action and connected action. The latter also contains two types, which are self-organizing networks and organizationally enabled networks (Bennett \& Segerberg, 2012, p. 756). In fact, their theory could also be understood as three action models on a parallel track because the organizationally enabled network is the hybrid of collective action and connected action. In the following part, this paper will identify whether the HK Alliance is collective or connected by analyzing its organization structure from three aspects — basic features, ideology and exclusiveness, and resource mobilization.

According to Bennett and Segerberg (2012, p. 749), a basic feature of collective action is getting individuals to contribute to some collective goals, and these goals are usually related to major social and political issues such as democratic reform. By contrast, a connected action does not require participants to contribute. The starting point of connected action is the self-motivated sharing of already internalized or personalized ideas and resources with networks of others (Bennett \& Segerberg, 2012, p.751-753). The nature of the HK Alliance could be seen from two aspects _ funding model and the way they organize activities. According to HK Alliance, their income mainly relies on digital donation and bank interest, and according to the financial report they published (Hong Kong Alliance Annual performance and financial report, 2019), the money was spent on activity funds, operating expenses, travel expenses, and funding other organizations. Recently, they started a new round of crowdfunding to extend the digital museum (June 4th museum, 2019). In terms of their funding model and the statement of fund use, it could be seen that the sponsors are not involved in deciding how to use the funding. The behavior of donating could be interpreted as complete agreement and support of HK Alliance's goals and actions, which strengthens the single conception and identity framing. A representative example is how HK Alliance built and extend the digital museum by crowdfunding. According to the statement, HK Alliance has decided how to extend the digital museum and what to display in the museum before launching the crowdfunding (June 4th museum, 2019), which means that the only way for the public to get involved is to donate. Therefore, the collective nature of the HK Alliance is obvious.

Similarly, the way how HK Alliance organizes activities shows the same collective logic. HK Alliance has organized various kinds of online and offline activities, and a common characteristic of those activities is that the form and content are preset. For example, HK Alliance once organized a songwriting workshop on Facebook in May 2018, which invited Facebook users to write a song with pre-determined lyrics ("Workshop on 64 requiem songwriting", 2018). By contrast, the Indignados, a typically connected movement, emphasized the personal action frames, which enabled participants to express their opinion in personalized forms (Bennett \& Segerberg, 2012, p.755). 
Secondly, a collective organization usually has a clear ideology and shows strong exclusiveness (Bennett \& Segerberg, 2012, p.751). As stated above, the organization plays an important role in both collective action and organizationally enabled networks. The difference lies in whether the organization intends to project strong agendas, political brands, and collective identities (Bennett \& Segerberg, 2012, p.756). In other words, whether the organization tends to realize its ideology or political appeals directly and exclusively from its action. For the HK Alliance, all the stated intentions show strong ideology and exclusiveness, and all its actions serve for stated goals. Specifically, the first three goals of HK Alliance require the Chinese communist party to confess its guilt and account for the massacre. However, what really happened on the Tian'anmen square that day is still controversial. Except for the complete denial of the Chinese government, some foreign reporters also gave out different voices. For example, the Daily Telegraph once reported that there was no bloodshed inside Tian'anmen Square (Moore, 2011). Also, the last two goals require a radical democratic revolution. However, whether a moderate reform or a radical revolution is more suitable to China is arguable as well, but all these voices are excluded in the HK Alliance's statement and actions.

Therefore, the organization structure and action modes of the HK Alliance are quite collective, which seems to run counter to the de-centralization trend of the digital space. However, in terms of the grim situation that HK Alliance faces, there is perhaps no other choice for them. As stated in the introduction, HK Alliance is different from other online movements like Occupy because the access to the information about the issue for the audience and potential participants is restricted, which requires HK Alliance to take the method of collective action to motivate as many resources as possible. McCarthy and Zald $(1973,1977)$ explained how the centralization and professionalization of an organization could enable more resource-intensive mobilization efforts. Bennett and Segerberg (2012, p. 750) also pointed out that a collective organization plays a crucial role in harnessing and coordinating resources and participants in the action. For HK Alliance, their goal is to change the Chinese political system and overthrow the ruling party. To achieve their goal, they need to gain the support of people. However, there is an obstacle in the route. Most of the targeted audience, Chinese people, is strictly restricted to access the resources, which means they do not have adequate knowledge to form self-motivation. Hence the connected action is unpractical. Therefore, an important mission of the HK Alliance at the current stage is to increase the public awareness of the June Fourth Incident, where collective action is necessary.

\section{Digital storytelling and HK Alliance}

To achieve political appeals, HK Alliance employs diversified digital methods to influence the public and political organizations. For example, similar to other online digital activism, HK Alliance also employs the symbolic packet strategy, which could accelerate the spread of information in the digital space through personal appropriation, imitation, and social sharing (Bennett \& Segerberg 2012, p. 746). Two most well-known symbols of HK Alliance are the Goddess of Democracy and the slogan "People will never forget." Goddess of Democracy is a sculpture resembling the statue of liberty, designed by students in 1989 (MacFarquhar, 1997). Lipschutz (2005) argued that such symbols enable meaning and discourse embedded in them to be culturally transmitted on a long-term basis. Compared with such frequently-used methods, the use of digital storytelling by HK Alliance is more interesting, and the performative of the story is representative. Therefore, this paper will focus on how the HK Alliance employs digital storytelling.

Digital storytelling refers to a digital expression form that people use new media technologies such as videos, blogs, and podcasts to tell stories that have happened to them from their own perspective. The accessibility and user-friendliness of new digital technology is the foundation of digital storytelling (Prono, 2017). Compared with traditional storytelling, digital facilities such as digital cameras, digital voice recorders, Windows MovieMaker, and iMovie make the digital story more flexible (Sylvester \& Greenidge, 2009, p. 284-295). Nowadays, digital storytelling is increasingly used for political purposes because of the strong affect appeal (Thrift 2004, p. 56). In digital storytelling, affect, and performative is considered as the core components. Affect 
is described as the stage before energy becomes matter which is moving between objects and bodies but is yet to impose definitive impressions upon either (Trimboli 2018, p. 46). Through some sort of performative, affect is propelled into, and implicated in, materiality (Butler, 1997).

The digital storytelling used by the HK Alliance has three main forms. The first one is the retrospect of the participants of June Fourth Incidence. The second one is the narration of the families of the victims, which usually reconstructs the scene of June Fourth Incidence with video and photo materials. The third one is the story told by the young people, which usually presents how they participate in the June fourth activity at present. In this part, this paper will compare two examples to analyze how they perform their stories and express affect to achieve different goals. The first one is the narration of a mother called Xianling Zhang, who lost her son in the June fourth Incidence. At the beginning of the video clip, an old and sorrowful face appeared with sad music, which is a common method in such videos. The face of a mother or other family is always shown in the close-up. Tomkins (1995, p. 89) thought that facial expression has the most considerable importance in producing the feel of affect. Zhang introduced herself as a seventy-two years old woman who lost her son twenty-one years ago. Then, when she was telling how she went to Tian'anmen square to find her son who had been killed by soldiers and buried in the yard of a middle school next to Tian'anmen square, her son's smiling photos and the video clips of the troops were presented synchronously (Zhang xianling, 2010). The whole story was performed around the sorrow of a mother who lost her son, and the purpose of seeking sympathy from the public is obvious, which is believed as the most effective method to transform affect into social passion (McClain, 2018).

Moreover, another purpose of such storytelling is to prove the massacre with various audiovisual materials. However, it is important to note that not all the materials could be verified in such kinds of videos. For instance, in this video, the photos and videos of troops are not directly related to the story, which means the audiovisual materials attached in this story could not prove that it was the soldier that killed her son. Therefore, a problem should be noted that compared with traditional storytelling, digital technologies enable people to manipulate the content, which makes it harder for the audience to distinguish the authenticity of the story.

The second example is the digital storytelling of Xiaoxin Tang, who is a graduate of Hong Kong University. The performative of this video is entirely different from the first one. The color tone is quite bright, and the music is peaceful. She presented her life as a volunteer and inserted her speech on the June Fourth anniversary in 2016. The video ended with her big smile in front of a picture of a tank (June 4th for young people, 2018). From this video, it could be seen that the affect is optimistic, aiming at calling the awareness and participation of young people, and passing the message of confidence.

Although the performative and affect of these two examples are different, they both realize the values of digital storytelling concluded by Lovvorn (2011, p. 97), including moving beyond organizations and becoming circulated on the internet, relating stories of the self in distinctive voices, and connecting the organization to the larger social world. Besides, the stylized forms of the digital story also indicate that the HK Alliance has a good understanding and application ability of digital technologies, which partly explains its greater influence than other similar organizations.

\section{Success or not?}

How to evaluate a movement or organization in the digital space has become an increasingly concerned topic in media research. Yana Breindl (2013), the researcher in Oxford internet institute, the University of Oxford, purposed three evaluation criteria, including,

1. Does the campaign generate awareness among the public? 
2. Are protest actors perceived as credible and legitimate interlocutors?

3. Does the campaign trigger concrete political or legal changes?

In terms of the first criterion, HK Alliance should be considered as outstanding. Since 1990, HK Alliance has organized 30 candlelight anniversaries on HongKong Victory square. The number of participants has kept increasing from 50,000 to 150,000 (Theme and work of previous June 4th anniversaries, 2018). This year, over 180,000 people gathered in Hong Kong to memorize the 30th anniversary of June Fourth Incidence ("Tens of thousands hold Tiananmen Square vigil", 2019). Besides, the memorial activities have spread to many parts of the world, including the United States, Australia, France, Taiwan, and Macao (Walden, 2019, Special to The New York Times, 1994, Taiwan holds first Tiananmen massacre commemoration in parliament, 2016), and many people in the Chinese mainland have also known the annual memorial in Hong Kong (Economy, 2019). Moreover, HK Alliance also plays a crucial role in generating awareness of global society. For example, Mike Pompeo, United States Secretary of State, called for the Chinese government to face up to the Tian'anmen Incidence during the memorial in 2018 (Ide \& Huang, 2018). Also, as stated above, HK Alliance has a mature organization structure, effective funding system, and the diversified digital strategies, which all makes it outstanding among other movements and organizations.

However, in terms of the other two criteria, the assessment of the effect of HK Alliance is controversial and complicated. First of all, the legitimate status of HK Alliance is in the blurry position. In the beginning, Szeto Wah, the then member of the Legislative Council of Hong Kong, founded the Hong Kong Alliance, which has been responsible for the annual memorials for the protests (Yu, 2013). According to the Hong Kong Bill of Rights Ordinance (1991) and Article 27 of the Basic Law of the Hong Kong Special Administrative Region of the People's Republic of China, the freedom of assembly is guaranteed by the laws of Hong Kong (Cheng 2018). Then, in 1992, considering the enactment of the 1991 Bill of Rights Ordinance and the Tiananmen Square Massacre of 1989, the Legislative Council of Hong Kong largely relaxed the restriction of Societies Ordinance, which made it almost zero entry barriers to set up a society (Li, 1997, p. 180). Therefore, HK Alliance and its activities during that period were legitimate. However, since Chinese government resumed the exercise of sovereignty over Hong Kong since July first, 1997, the 1992 amendments to the Societies Ordinance were rolled back by the Beijing-controlled Provisional Legislative Council (PLC). In 2002, the Hong Kong government introduced the article 23 of Hong Kong Basic Law into the legislative process, which included prohibiting foreign political organizations or organizations from carrying out political activities in the Hong Kong special administrative region, and prohibiting the political organisations in Hong Kong from establishing ties with foreign political organizations or organizations. This article was thought to aim at HK Alliance, and prompted half a million people to march against the legislation on July first (Wong, 2004). In 2018, the juristic reasons "national security, public safety, public order, protection of freedom and rights of others." were added to Societies Ordinance, and the Hong Kong government officially declared HKNP, a more radical political organization, to be an illegal society (Aljazeera, 2018). Overall, it could be seen that the legitimate status of HK Alliance is actually arguable. Whereas at present, the operation of HK Alliance is open and transparent to the public, meaning it is easy to find the contact information, address, organization members, and the financial report, and the online and offline activities are going on as usual. In fact, the Hong Kong government takes the attitude of acquiescence, which is rooted in the more profound and intricate relationship between Hong Kong government and the Chinese government.

The last criterion - Does the campaign trigger concrete political or legal changes, is more complicated and could trigger the rethink of assessing a digital organization. From today's perspective, it is hard to say that HK Alliance has fully realized any one of its five political goals. Any discussions of June fourth Incidence are strictly forbidden in Chinese mainland. Besides, the terms like "64" and "June fourth," for instance, are sensitive words that cannot be shown on the Chinese internet ("Skype Defends VoIP IM Monitoring In China", 2008). 
Needless to say, it is still far to see a democratic China. However, under the increasing pressure of the ongoing protest in Hong Kong, Carrie Lam, the current Chief Executive of Hong Kong, finally declared to withdraw the bill on September fourth, 2019 (Griffiths, 2019). Technologically, this is exactly a legal change, which meets the criterion, but it is not generated from the original political appeals.

Overall, HK Alliance fully meets the first criterion, actually meets the second criterion, and partially, or saying technologically, meets the third criterion. Therefore, in terms of Breindl's framework, HK Alliance should be seen as a successful organization. But at the same time, it is obvious that such framework could not fully unfold the role and the impact of HK Alliance. As Nedelcu (2012) argued, the core features of digital technologies are simultaneity and intensity, which generates the rapid and endless movement in the digital space. Given this, the agents, including individuals, organisations, and digital platforms, all show the dynamic characteristic. However, Breindl's evaluation framework is static, which contradicts the nature of the digital age.

Furthermore, Breindl's evaluation framework is also results-oriented. However, for a digital organisation with strong political appeals, particularly in the excessively intricate region like China, the values produced in the process should not be ignored as well. The existence and operation of the HK Alliance indeed unit the power of not only Chinese people but people across the world, and increase the influence of democracy promoting organisations. Besides, it also keeps precious materials about June Fourth Incidence. All these 'processes' have significant values for the general process of democratization in China. Therefore, the static and results-oriented evaluation criterion seems not appropriate in the current digital space. On the contrary, a dynamic appraisal method which does not only assesses the result but also considers the value of the process should get more attention in future research.

\section{Conclusion}

The positive effect of digital technologies in assisting Hong Kong Alliance to promote democratization should be recognized. The development process of the HK Alliance well reflects how digital technology influences and reshapes the organization structure and operation mode of a traditional activism organization. On the one hand, digital space has dramatically expanded the source of resources and donations of HK Alliance, and enhance its ability to mobilize as much resource as possible through the collective mode. On the other hand, the good use of digital technologies by HK Alliance increases the impact of its actions. For example, the well-edited and stylized digital storytelling catches the affect of the targeted audience and effectively transform the emotion into power.

HK Alliance has generated significant public awareness in the past thirty years. Hundreds of thousands of people have walked on the street to cherish the memory of victims in the June Forth Incidence, and called for radical democratization reform. Compared with this, the legitimate status of HK Alliance could not be simply identified by the legal provision or a fait accompli. The subtle position that HK Alliance currently lies is a result of the power struggle among the Chinese government, civil force, and Hong Kong government, but at least varied actions of HK Alliance are still operated under the sun at present. More importantly, the ongoing protest in Hong Kong reminds people to review the popular evaluation criterion that overexposes the static results rather than more deeply understands the meaning and the actual effect of organizations like HK Alliance. When the antidemocratic events like the Fugitive Offenders amendment bill emerge, HK Alliance immediately plays the leading role in the protest movement, even if it is not directly related to its original political goals.

\section{References}

Bennett, W. L., \& Segerberg, A. (2012). The logic of connective action: Digital media and the personalization of contentious politics. Information, Communication \& Society, 15(5), 739-768. https://doi.org/10.1080/1369118X.2012.670661 
Branigan, T. (2009, June 2). China blocks twitter, flickr, youtube and hotmail ahead of tiananmen anniversary. The Guardian. Retrieved 12 March 2020 from https://www.theguardian.com/technology/2009/jun/02/twitterchina

Breindl, Y. (2013). Assessing success in internet campaigning: The case of digital rights advocacy in the european union. Information, Communication \& Society, 16(9), 1419-1440. https://doi.org/10.1080/1369118X.2012.707673

Briggs, A., \& Burke, P. (2009). A social history of the media: From Gutenberg to the Internet (3rd ed). Cambridge, UK; Malden, MA: Polity.

Brook, T. (1998). Quelling the people: The military suppression of the Beijing democracy movement. Stanford, Calif: Stanford University Press.

Butler, J. (1988). Performative acts and gender constitution: An essay in phenomenology and feminist theory. Theatre Journal, 40(4), 519. https://doi.org/10.2307/3207893

Calhoun, C. (1989). Revolution and repression in Tiananmen square. Society, 26(6), 21-38. https://doi.org/10.1007/BF02700237

Chadwick, A. (2007). Digital network repertoires and organizational hybridity. Political Communication, 24(3), 283-301. https://doi.org/10.1080/10584600701471666

Cheng, K. (2018, July 19). Explainer: How Hong Kong is seeking to ban a pro-independence party using existing national security laws. Retrieved 11 March 2020, from Hong Kong Free Press HKFP website: https://www.hongkongfp.com/2018/07/19/explainer-hong-kong-seeking-ban-pro-independence-party-usingexisting-national-security-laws/

Clay Shirky. (2011). The Political Power of Social Media: Technology, the Public Sphere, and Political Change. Foreign Affairs, 90(1), 28.

Economy, E. (2019). 30 years after tiananmen: Dissent is not dead. Journal of Democracy, 30(2), 57-63. https://doi.org/10.1353/jod.2019.0024

Griffiths, J. (2019, September 4). After months of protests, Hong Kong leader withdraws extradition bill [News]. Retrieved 14 March 2020, from CNN/Asia website: https://www.cnn.com/2019/09/04/asia/hong-kongcarrie-lam-extradition-bill-intl-hnk/index.html

Habermas, Jürgen. (1999). The Structural transformation of the public sphere: An inquiry into a category of bourgeois society (10. print). Cambridge, Mass: MIT Press.

Habermas, Jurgen, Lennox, S., \& Lennox, F. (1974). The public sphere: An encyclopedia article(1964). New German Critique, (3), 49. https://doi.org/10.2307/487737

Haffner, M. (2019). A place-based analysis of \#BlackLivesMatter and counter-protest content on Twitter. GeoJournal, 84(5), 1257-1280. https://doi.org/10.1007/s10708-018-9919-7

Hansson,K.,Sveningsson, M.,Sandgren,M , \& Ganetz, H. (2019)."We passed the trust on": Strategies for security in\# MeToo activism in Sweden. (2019). Reports of the European Society for Socially Embedded Technologies Proceedings of 17th European Conference on Computer-Supported Cooperative Work, 1.Retrieved 14 March 2020, from https://doi-org.ezp.lib.unimelb.edu.au/10.18420/ecscw2019_ep14

Hong Kong: Pro-independence party faces possible ban [News ]. (2018, July 18). Retrieved 9 March 2020, from NEWS/HONG KONG website: https://www.aljazeera.com/news/2018/07/hong-kong-pro-independence-partyfaces-ban-180717183723305.html

Hong Kong Alliance. (2015, October 6). Retrieved 9 March 2020, from Hong Kong Alliance in Support of Patriotic Democratic Movements of China website: https://hka8964.wordpress.com/hkaeng/

Hong Kong Alliance Annual performance and financial report. (2019, September 12). Retrieved 9 March 2020, from Hong Kong Alliance in Support of Patriotic Democratic Movements of China website: https://hka8964.wordpress.com/hkalliance/report/

Ide, B., \& Huang, J. (2018). Calls for china to face ghosts of its past on tiananmen anniversary | voice of america - English. Retrieved 14 March 2020, from https://www.voanews.com/east-asia-pacific/calls-china-faceghosts-its-past-tiananmen-anniversary 
June 4th for young people-Xiaoxin Tang. (2018). Retrieved 14 March 2020, from Youtube website: https://www.youtube.com/watch?v=YPmsg78fHu0

《June 4th museum》 official blog: crowdfunding for reopening a larger june 4th museum. (2019). Retrieved 3 March 2020, from 《June 4th Museum》 Official Blog website: https://64museum.blogspot.com/2016/07/cfunding.html

Kaun, A. (2017). 'Our time to act has come': Desynchronization, social media time and protest movements. Media, Culture \& Society, 39(4), 469-486. https://doi.org/10.1177/0163443716646178

Li, Pang-kwong (Eds.). (1997). Political order and power transition in Hong Kong. Hong Kong: Chinese University Press.

KIRSTY, H. (2012). Free Speech in the Digital World under Threat? Economic and Political Weekly, 47(46), 18.

Li, Peter, Mark, S., Li, M. H., \& Hoopla digital. (2011). Culture and politics, china: An anatomy of tiananmen square. United States: Transaction Publishers : Made available through hoopla.

Lim, L. (2014). The People's Republic of amnesia: Tiananmen revisited. New York, NY: Oxford University Press.

Lipschutz, R. (2005). Power, politics and global civil society. MILLENNIUM-JOURNAL OF INTERNATIONAL STUDIES, 33(3), 747-769.

Lovvorn, J. (2012). 'Theorizing Digital Storytelling: From Narrative Practice to Racial Counterstory.' Narrative acts: Rhetoric, race and identity, knowledge (D. Journet, B. A. Boehm, \& C. E. Britt, Eds.). New York, NY: Hampton Press.

Longe, O. B., Danquah, P., \& Ebem, D. U. (2012). De-individuation, anonymity and unethical behavior in cyberspace--explorations in the valley of digital temptations. Computing and Information Systems, 1, 46.

MacFarquhar, R. (Eds.). (1997). The politics of china: The eras of mao and deng (2nd ed). New York: Cambridge University Press.

McChesney, R. (2013).'The Internet and Capitalism I: Where Dinosaurs Roam?', in Digital Disconnect: How Capitalism is Turning the Internet Against Democracy, The New Press, New York, pp.96-129.

McClain, D.C. (2018). Regulating Feeling in the First American Novel: Sympathy, Sensibility, and Sentiment in William Hill Brown's The Power of Sympathy. Studies in American Fiction 45(2), 143-164. doi:10.1353/saf.2018.0007.

McCarthy, J. D., \& Zald, M. N. (1987). The Trend of Social Movements in America: Professionalization and Resource Mobilization. In Social Movements in an Organizational Society (p. 337).

Miles, J. A. R. (1997). The legacy of Tiananmen: China in disarray. Ann Arbor: University of Michigan Press.

Moore, M. (2011, June 4). Wikileaks: No bloodshed inside Tiananmen Square, cables claim. Retrieved 14 March 2020, from https://www.telegraph.co.uk/news/worldnews/wikileaks/8555142/Wikileaks-no-bloodshedinside-Tiananmen-Square-cables-claim.html

Nakamura, L. (2008). Digitizing race. [electronic resource]: visual cultures of the Internet. University of Minnesota Press.

Nedelcu, M. (2012). Migrants' new transnational habitus: Rethinking migration through a cosmopolitan lens in the digital age. Journal of Ethnic and Migration Studies, 38(9), 1339-1356. https://doi.org/10.1080/1369183X.2012.698203

Prono, L., PhD. (2019). Digital Storytelling. Salem Press Encyclopedia.

Ruth, M. (2018). Social Media and Political Campaigns. Salem Press Encyclopedia.

Special to The New York Times (1994, June 5). "Symbol of Tiananmen Square is Resurrected". Retrieved 14 March 2020, from New York Times

https://www.nytimes.com/1994/06/05/us/symbol-of-tiananmen-square-is-resurrected.html

Sylvester, R., \& Greenidge, W. (2009). Digital storytelling: Extending the potential for struggling writers. The Reading Teacher, 63(4), 284-295. https://doi.org/10.1598/RT.63.4.3

Siegert, G., Rimscha, B. von, \& Grubenmann, S. (2017). Commercial communication in the digital age: Information or disinformation? Boston/Berlin: De Gruyter. 
Skype Defends VoIP IM Monitoring In China; Sensitive words include references to the Chinese Communist Party, the Falun Gong, Taiwan independence, Tibet, and the ongoing tainted milk scandal in China. (2008). InformationWeek.

Taiwan holds first Tiananmen massacre commemoration in parliament | Hong Kong Free Press HKFP. (2016). Retrieved 14 March 2020, from https://www.hongkongfp.com/2016/06/04/taiwan-holds-first-tiananmencommemoration-parliament/

Tens of thousands hold Tiananmen Square vigil. (2019, June 4). BBC News. Retrieved 14 March 2020, from BBC News: https://www.bbc.com/news/world-asia-china-48516455

Thrift, N. (2004). Intensities of feeling: Towards a spatial politics of affect. Geografiska Annaler: Series B, Human Geography, 86(1), 57-78. https://doi.org/10.1111/j.0435-3684.2004.00154.x

Thomas, A. (2006). The Tank Man | FRONTLINE | PBS. Retrieved 20 May 2019, from https://www.pbs.org/wgbh/pages/frontline/tankman/

Theme and work of previous June 4th anniversaries. (2018, September 28). Retrieved 14 March 2020, from Hong Kong Alliance in Support of Patriotic Democratic Movements of China website:

https://hka8964.wordpress.com/process/hkaeventhistory/

Tomkins, S. S., \& Demos, E. V. (1995). Exploring affect: The selected writings of Silvan S. Tomkins. Cambridge [England]; New York: Paris: Cambridge University Press; Editions de la Maison des sciences de l'homme.

Trimboli, D. (2018). Affective everyday media: The performativity of whiteness in australian digital storytelling. Critical Arts, 32(3), 44-59. https://doi.org/10.1080/02560046.2018.1488879

Walden, M. (2019). The Australian Chinese granted residency after Tiananmen Square. Retrieved 14 March 2020, from https://www.aljazeera.com/news/2019/06/australian-chinese-granted-residency-tiananmen-square190602232721328.html

Wong, Y. (2004). 《One country, two systems》 in crisis: Hong Kong's transformation since the handover. Lanham: Lexington Books.

Workshop on 64 requiem songwriting. (2018). Retrieved 5 March 2020, from HK Alliance facebook: https://www.facebook.com/events/181441732672573/

World's largest monument to the 1989 Tiananmen massacre unveiled ahead of 30th anniversary. (2019, February 25). Retrieved 14 March 2020, from Hong Kong Free Press HKFP website: https://www.hongkongfp.com/2019/02/25/worlds-largest-monument-1989-tiananmen-massacre-unveiled-ahead30th-anniversary/

\#YouKnowMe: Celebrities share abortion stories after Alabama ban. (2019, May 17). Retrieved 2 March 2020, from Evening Standard website: https://www.standard.co.uk/showbiz/celebrity-news/alabama-abortion-law-banrihanna-jameela-jamil-a4144696.html

Yu, L., Recker, M., Chen, S., Zhao, N., \& Yang, Q. (2018). The moderating effect of geographic area on the relationship between age, gender, and information and communication technology literacy and problematic internet use. Cyberpsychology, Behavior, and Social Networking, 21(6), 367-373. https://doi.org/10.1089/cyber.2017.0503

Yu,C.C/卓育至(2013). Hong Kong"s democratic movement and facing China: The vision and course of Szeto Wah. National Taiwan university, Taipei, Taiwan. Retrieved 14 March 2020, from https://hdl.handle.net/11296/36p9d5

Zhang xianling, representative of the 《Tian'anmen mothers》, the 21st anniversary of the June 4th movement. (2010). Retrieved 14 March 2020, from Youtube website:

https://www.youtube.com/watch?v=hY1ufCaN73A\&list=PLIQWh5-

ZBqdLNtVS1GIurQvJecAVWUHWD\&index $=2$

ZUCKERMAN, E. (2012, June 30). Worldchanging | evaluation + tools + best practices: The cute cat theory of digital activism [Open-source database]. Retrieved 14 March 2020, from WORLDCHANGING website: https://web.archive.org/web/20120630231006/http://www.worldchanging.com/archives/007877.html 